\title{
Economic policy uncertainty and Bitcoin. Is Bitcoin a safe-haven asset?
}

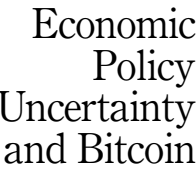

Jessica Paule-Vianez, Camilo Prado-Román and Raúl Gómez-Martínez Department of Business Economics, Universidad Rey Juan Carlos, Madrid, Spain

\begin{abstract}
Purpose - The goal of this work is to determine whether Bitcoin behaves as a safe-haven asset. In order to do so, the influence of Economic Policy Uncertainty (EPU) on Bitcoin returns and volatility was studied.

Design/methodology/approach - It is evaluated whether, when compared with the evolution of EPU, Bitcoin's returns and volatility show behaviours typical of safe havens or rather, those of conventional speculative assets. When faced with an increase in EPU, safe havens - such as gold - can be expected to increase their returns and volatility, while conventional speculative assets will increase their volatility and reduce their returns. This study uses simple linear regression and quantile regression models on a daily data sample from 19 July 2010 to 11 April 2019, to analyse the influence of EPU on the returns and volatility of Bitcoin and gold.

Findings - Bitcoin's returns and volatility increase during more uncertain times, just like gold, showing that Bitcoin acts not only as a means of exchange but also shows characteristics of investment assets, specifically of safe havens. These findings provide useful information to investors by allowing Bitcoin to be considered as a tool to protect savings in times of economic uncertainty and to diversify portfolios.

Originality/value - This study complements and expands current research by aiming to answer the question of whether Bitcoin is a simple speculative asset or a safe haven. The most significant contribution is to show that Bitcoin is not a mere speculative asset but behaves like a safe haven.
\end{abstract}

Keywords Bitcoin, Economic policy uncertainty, Safe-haven asset, Speculative asset

Paper type Research paper

\section{Introduction}

After the outbreak of the global financial crisis and the consequent loss of confidence in the existing financial system along with extreme uncertainty regarding economic policy measures that would be taken by governments and central banks, Nakamoto (2008) proposes an alternative to conventional fiduciary currencies by creating the "digital currency" Bitcoin.

Since Bitcoin was launched, its value has grown rapidly going from $\$ 0.09$ on 18 July 2010, to a historical high of $\$ 19,870.6$ on 17 December 2017. This rapid increase has motivated a growing interest in the literature to understand the economic and financial determinants that may influence Bitcoin's price (Demir et al., 2018), since the behaviour of this virtual currency seems to be independent of economic and financial developments (Kristoufek, 2015; Polasik et al., 2015). Several studies argue that in times of economic instability and low confidence in common economic and financial structures, the attractiveness of Bitcoin increases (Bouri et al., 2017a; Luther and Salter, 2017; Demir et al., 2018; Fang et al., 2019). In this line, it has been argued that Bitcoin could act as a solution to the inefficiency of these structures by using it as a hedging instrument against the stock market (Dyhrberg, 2016; Bouri et al., 2017a; Demir et al., 2018; Selmi et al., 2018; Guesmi et al., 2019; Fang et al., 2019).

(C) Jessica Paule-Vianez, Camilo Prado-Román and Raúl Gómez-Martínez. Published in European Journal of Management and Business Economics. Published by Emerald Publishing Limited. This article is published under the Creative Commons Attribution (CC BY 4.0) licence. Anyone may reproduce, distribute, translate and create derivative works of this article (for both commercial and non-commercial purposes), subject to full attribution to the original publication and authors. The full terms of this licence may be seen at http://creativecommons.org/licences/by/4.0/legalcode.

Received 17 July 2019 Revised 10 December 2019 2 January 2020

Accepted 11 January 2020 
EJMBE 29,3

\section{8}

Although the possibility of Bitcoin acting as a hedging and safe-haven instrument against economic uncertainty has been suggested, Bitcoin is not exempt from criticism. Its speculative nature (Cheah and Fry, 2015; Baur et al., 2018; Eom et al., 2019), bubble formation tendencies (Cheah and Fry, 2015; Corbet et al., 2018; Bouri et al., 2019), high price volatility (Brandvold et al., 2015; Eom et al., 2019; Aalborg et al., 2019) and the scandals and frauds that have accompanied it (Selmi et al., 2018), have generated a debate regarding its suitability and role in the financial system. Is it a simple means of exchange and a store of value, a speculative asset or a safe haven?

Consequently, the purpose of our research is to study the role that Bitcoin plays when confronted with Economic Policy Uncertainty (EPU). Can it act as a hedge or safe haven in the face of economic uncertainty due to its independence from the existing economic and financial system or should it be considered as a speculative asset due to its high volatility? To achieve this, we study the influence of EPU on the returns and volatility of Bitcoin and gold, with EPU being understood as the "non-zero probability of changes in existing economic policies" (Baker et al., 2016). This is one of the first studies that evaluates the role played by Bitcoin taking into account the return and volatility behaviour of this cryptocurrency in the face of variations in EPU. This approach to determine the role played by Bitcoin is adequate because (1) the influence of EPU on the volatility of Bitcoin allows us to determine whether this cryptocurrency can be considered as a simple means of exchange or as an investment asset and (2) the impact of EPU on the return of this cryptocurrency allows us to determine whether Bitcoin can be considered as a simple speculative asset or as a refuge value. It could be expected that when investors are faced with uncertainty regarding future fiscal, regulatory and monetary policies, hedges or safe-haven assets will increase their returns and volatility while typical speculative assets will increase their volatility but reduce their returns. Likewise, another important contribution of this study is the distinction of the influence of EPU in the return and volatility of Bitcoin by quantiles, being outstanding to know the behaviour of the return and volatility of Bitcoin against EPU in times of greater and lesser EPU.

By using the EPU measure of Baker et al. (2016) on the daily returns and volatility of Bitcoin and gold from 19 July 2010 to 11 April 2019, it was found that EPU has a positive impact on Bitcoin returns and volatility at higher quantiles, just like gold. These results demonstrate that Bitcoin does not act as a simple means of exchange, the main purpose for which it was created, but rather that it presents characteristics of investment assets, specifically of safe havens. These findings allow investors to consider this asset as a tool to protect their savings in times of economic uncertainty and build diversified portfolios including Bitcoin.

From here, the work is structured as follows:

In Section 2, we review the existing literature in our area of study. Section 3 lays forth the data used for our research. In Section 4, we discuss our methodological choices. Section 5 contains our results and leads into Section 6 , where we examine and explain the conclusions of the study.

\section{Literature review}

Since its launch, Bitcoin has attracted the attention of professionals, academics and the media due to its exclusive decentralized payment system based on Blockchain technology (Wang et al., 2018) and independency from sovereign governments, centralized institutions and banking systems (Fang et al., 2019).

One of the issues that have generated the most interest is the understanding of Bitcoin price determinants. Thus, several studies have tried to explain and predict the price of Bitcoin, such as Kristoufek (2013) demonstrates that it is difficult to explain Bitcoin prices 
using standard financial theory, and Aalborg et al. (2019) determined that the price of Bitcoin is unpredictable, even though its volatility can be predicted by its past values. This lack of understanding of the formation of Bitcoin prices has generated a debate around its role.

The fact that Bitcoin is a decentralized currency, independent of sovereign governments, centralized institutions and banking systems (Fang et al., 2019) has suggested that Bitcoin may be part of an alternative economy (Bouri et al., 2017b). In this way, it becomes possible for Bitcoin to act as an instrument for hedges or safe havens in the face of loss of confidence in the economic system. However, its speculative nature (Cheah and Fry, 2015; Baur et al., 2018; Eom et al., 2019), bubble formation tendencies (Cheah and Fry, 2015; Corbet et al., 2018; Bouri et al., 2019), high price volatility (Brandvold et al., 2015; Eom et al., 2019; Aalborg et al., 2019) and the scandals and frauds that have accompanied it (Selmi et al., 2018), create questions as to whether this asset can be considered a safe-haven asset. Is it acting as an exchange instrument or rather, as a simple speculative asset? In this line, several works have tried to explain its role by relating its behaviour to stocks (Bouri et al., 2017b; Fang et al., 2019), bonds (Bouri et al., 2017b; Fang et al., 2019), commodities (Bouri et al., 2017b; Bouri et al., 2018a; Selmi et al., 2018; Shahzad et al., 2019; Fang et al., 2019), gold (Bouri et al., 2017b; Bouri et al., 2018a; Al-Khazali et al., 2018; Selmi et al., 2018; Shahzad et al., 2019), conventional currencies (Bouri et al., 2017b), financial stress (Bouri et al., 2018b) and EPU (Bouri et al., 2017a; Demir et al., 2018; Selmi et al., 2018; Wang et al., 2018; Fang et al., 2019).

The great recovery capacity of Bitcoin during periods of turbulence has suggested the possibility of this cryptocurrency acting as a hedging instrument and a safe haven against global uncertainty (Selmi et al., 2018). According to Weber (2014), Bitcoin benefited from the uncertain economic environment that followed the 2008 crisis. During these periods of turbulence, many saw Bitcoin as a safe haven against the uncertainty surrounding conventional banking and economic systems (Bouri et al., 2017a). In addition, its low transaction costs contributed to an increase in the demand for Bitcoins (Ciaian et al., 2016).

Based on the above proposition, an emerging area of the literature investigates the possible relationship between the behaviour of Bitcoin and economic uncertainty to justify its possible function as a safe haven. Bouri et al. (2017a) examined whether Bitcoin could hedge global uncertainty, measured by the first principal component of the Volatility Indices (VIX) of 14 developed and developing equity markets, finding that Bitcoin acts as a diversifier, a hedge or a safe haven against uncertainty. Al-Khazali et al. (2018) analysed the impact of positive and negative macroeconomic news surprises on gold and Bitcoin, finding that, although gold reacted systematically to such surprises in a consistent way with its role as a safe-haven asset, Bitcoin did not react in a similar way. Selmi et al. (2018) evaluated the role of Bitcoin as a safe haven, a hedge and/or a diversifier for extreme oil price movements, compared to gold. They show how both Bitcoin and gold fulfil the functions of a safe haven and diversifier for oil price movements, concluding that both Bitcoin and gold are assets in which investors can deposit their cash during moments of political and economic turmoil. Demir et al. (2018) use the EPU measure of Baker et al. (2016) to predict Bitcoin returns. The document finds that EPU has a predictive power on Bitcoin returns, finding an overall negative effect. However, when differentiating by quantiles, they discover that the effect is positive and significant at the lowest and highest quantiles, concluding that Bitcoin can serve as a hedge against uncertainty. Wang et al. (2018) investigated the effect of the risk derived from EPU on Bitcoin, proposing that if Bitcoin is independent of the existing economic and financial system, EPU would not affect it. By using the EPU index and the Equity Market Uncertainty index of Baker et al. (2016), as well as the VIX as proxies of EPU, they find that the risk spillover effect from EPU to Bitcoin is insignificant and, therefore, Bitcoin could act as a safe haven or diversifier of EPU. Fang et al. (2019) analysed the influence of EPU on the long-term

\section{Economic Policy \\ Uncertainty and Bitcoin}


EJMBE 29,3

volatility of Bitcoin, global stocks, commodities and bonds, finding that EPU influenced the volatility of Bitcoin, stocks and commodities, but not bonds. At the same time, they discovered that EPU has a significant negative impact on the Bitcoin-Bonds correlation, and a positive impact on the Bitcoin-stocks and Bitcoin-commodities correlations, which leads to suggesting the possibility of Bitcoin to act as a hedge under specific economic uncertainty conditions. However, they determine that the effect found is weak.

Meanwhile, an alternative line of research defends a more speculative role for this cryptocurrency. Bitcoin price booms and crashes motivated Cheah and Fry (2015) to study whether Bitcoin could be developing speculative bubbles, finding that Bitcoin prices contain a substantial speculative bubble component (Dowd, 2014), and that the fundamental value of this cryptocurrency is zero. Other authors investigating the possible existence of speculative bubbles in the formation of Bitcoin prices are Corbet et al. (2018). Using as underlying fundamentals of the Bitcoin price, the blockchain position, the hash rate and liquidity as measured by the volume of daily transactions, they find that Bitcoin goes through some bubble periods. Bouri et al. (2019) studied the explosiveness of Bitcoin prices and identify the formation of speculative bubbles in this cryptocurrency. In turn, the volatility of this cryptocurrency has been criticized. In their study on the discovery of Bitcoin prices, Brandvold et al. (2015) showed the high temporal volatility of this cryptocurrency. Similarly, Eom et al. (2019) find that investor sentiment shows a significant power of explanation for changes in Bitcoin volatility, concluding that Bitcoin seems to be an investment asset with high volatility and dependence on sentiments rather than a medium of exchange. These same authors suggest that these findings support the literature that finds that Bitcoin has characteristics of speculative assets. Another study that defends the role of Bitcoin as a speculative asset is that of Baur et al. (2018). These authors analyse whether Bitcoin is a medium of exchange or a speculative asset, showing how Bitcoin is used mainly as a speculative investment and not as a simple medium of exchange.

Based on the above proposition, the aim of our research is to study whether Bitcoin acts as a means of exchange, a safe-haven value or refuge or a speculative asset.

\section{Data}

To study the influence of EPU on the returns and volatility of Bitcoin and gold, we extracted daily data of EPU, Bitcoin and gold for the period spanning from 19 July 2019 to 11 April 2019.

As a measure of EPU, we chose the daily US EPU index based on Baker et al. (2016) (http:// www.policyuncertainty.com). This index is constructed based on the number of newspaper articles in the US that contain, at least, the following combination of terms: "economy" or "economic"; "uncertain" or "uncertainty" and "legislation", "deficit", "regulation", "Congress", "Federal Reserve" or "White House".

Figure 1 shows the evolution of EPU for the period that is under study. We find that EPU is at its highest around events such as the Brexit, the Eurozone crisis, the US debt crisis and the US "fiscal cliff."

To analyse Bitcoin returns and volatility, we collected daily data on US $\$$ prices for Bitcoin from investing (https://www.investing.com). Figure 2 shows the evolution of Bitcoin's price, highlighting its high growth during 2017 and subsequent fall in 2018.

For gold, we collected daily data on US $\$$ prices from investing (https://www.investing. com). Figure 3 shows the evolution of the price of gold, highlighting how the highest gold prices occurred between 2011 and 2013, a period in which the effects of the global financial crisis were still being felt.

As a measure of the returns of Bitcoin and gold, we use the variation rate of the quoted prices on consecutive days, that is: 


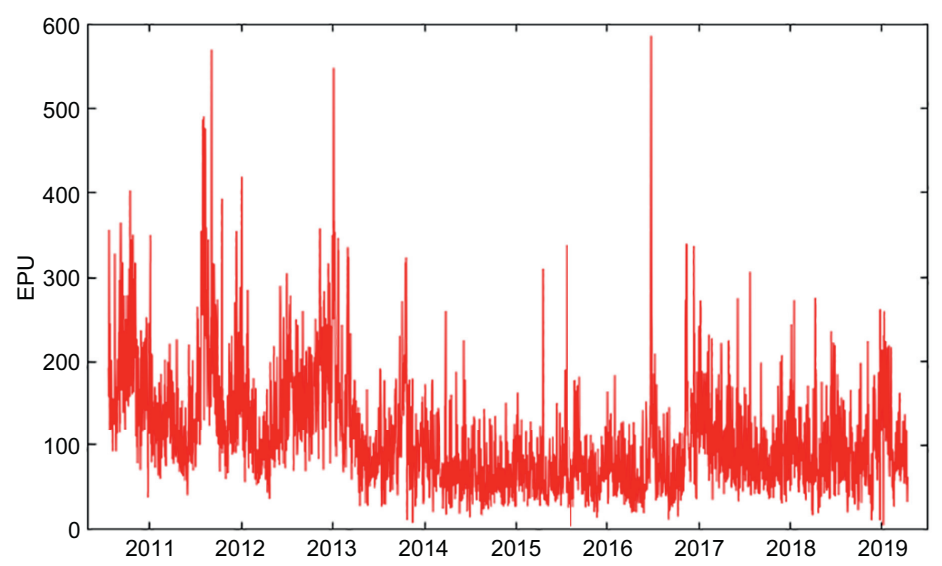

Economic

Policy

Uncertainty

and Bitcoin

351

Figure 1.

Economic policy uncertainty for the period 19 July 2010-11

April 2019

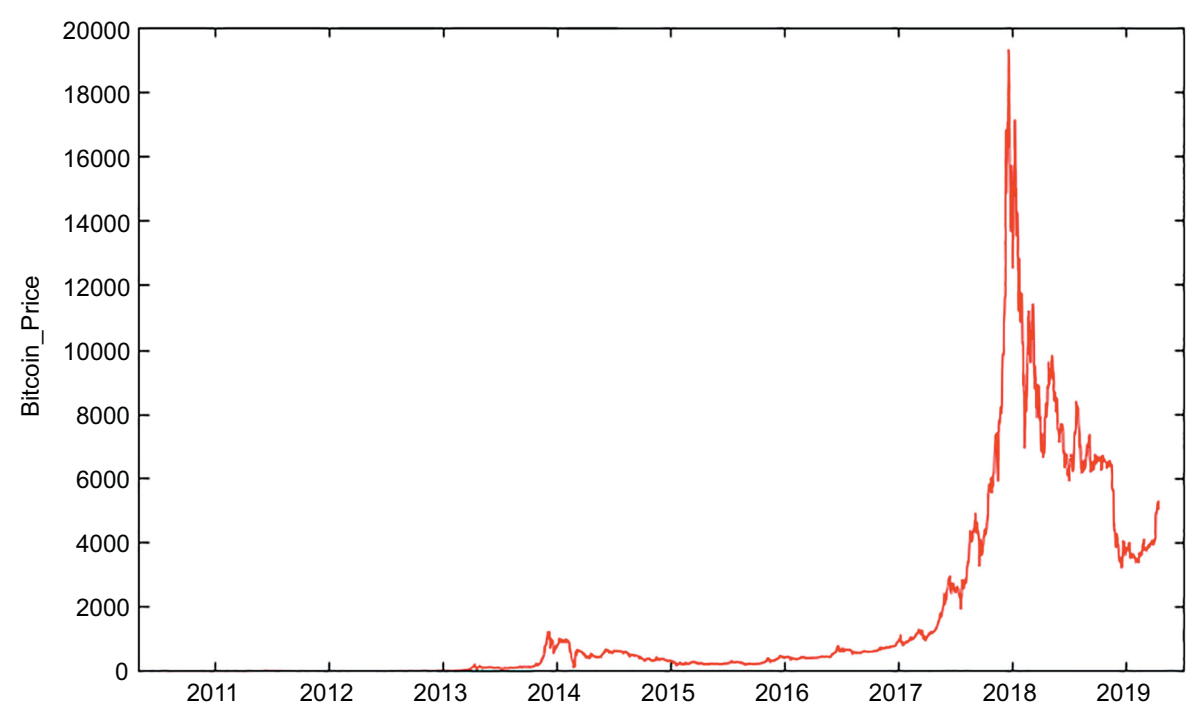

Figure 2.

Bitcoin price for the period 19 July 2010-11 April 2019

$$
R_{i, t}=\frac{P_{i, t}-P_{i, t-1}}{P_{i, t-1}}
$$

where $R_{i, t}$ represents the return on asset $i$ on day $t$ and $P_{i, t}$ the closing price of asset $i$ on day $t$.

To study volatility, we chose two proxy measures to account for the lack of consensus on the more appropriate volatility proxy as well as the possible sensitivity of the results to the choice of proxy.

Following the measure proposed by Chen and Zheng (2008), daily volatility is estimated as the difference between the highest quoted price reached minus the lowest quoted price obtained on the day, divided by the average of both, that is: 


\section{EJMBE 29,3}

\section{2}

Figure 3.

Gold price for the period 19 July $2010-11$ April 2019

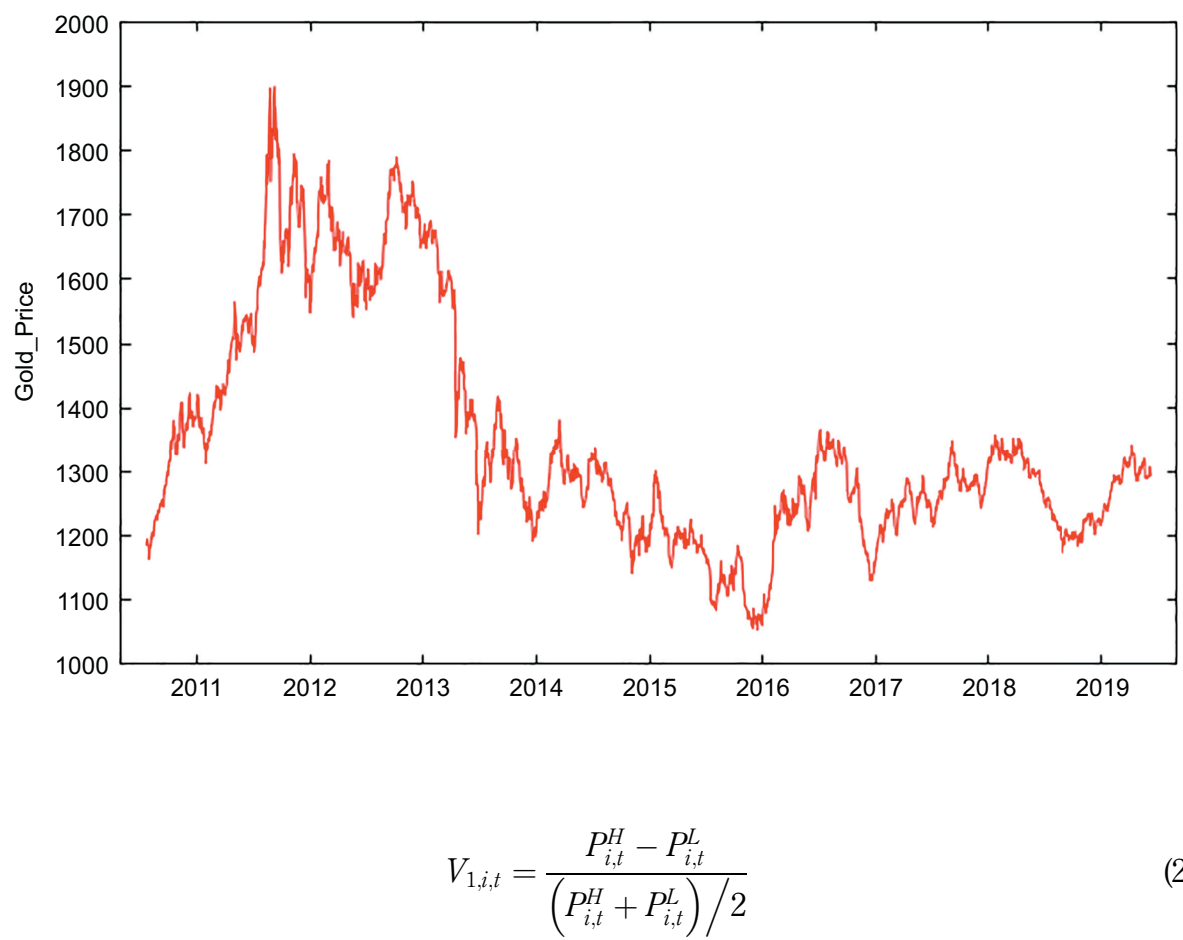

where $V_{1, i, t}$ represents the volatility of the asset $i$ on day $t$ with this estimator, $P_{i, t}^{H}$ the maximum price of the asset $i$ on day $t$ and $P_{i, t}^{L}$ the minimum price of the asset $i$ on day $t$.

The other measure we used to estimate daily volatility is Parkinson's volatility (1980), which is the most frequent range-based volatility estimator (Molnár, 2012). This estimator, based on the differences between high and low prices, is considered much less noisy than squared yields (Huisman et al., 2012), that is:

$$
V_{2, i, t}=\sqrt{365} \sqrt{\frac{\ln \left(P_{i, t}^{H} / P_{i, t}^{L}\right)^{2}}{4 \ln (2)}}
$$

where $V_{2, i . t}$ represents the volatility of the asset $i$ on day $t$ with this estimator.

Table I shows the descriptive statistics of the EPU levels, the returns and volatility of Bitcoin and the returns and volatility of the gold. It highlights how gold returns show the highest dispersion (measured by its coefficient of variation (CV)), followed by Bitcoin's returns, reaching maximum daily returns of 5.29 per cent and 336.75 per cent, respectively. As for asymmetry and kurtosis, their coefficients reveal that all the analysed variables are biased and have a leptokurtic distribution, especially marked in the Bitcoin returns. These findings clearly show that the distributions of these variables are not normal, so they provide a good motivation to apply a quantile-based approach to adapt to extreme values.

\section{Methodology}

We used simple linear regression with ordinary least squares to study the influence of EPU on the conditional expectation of the returns and volatility of Bitcoin and gold and quantile 
regression to study the influence of $\mathrm{EPU}$ on the extreme quantiles of the return and volatility of Bitcoin and gold.

Our descriptive analysis shows that the variables under the study are not normal, with long tails to the right and high kurtosis. This suggests the appropriateness of applying a quantile-based approach. At the same time, since the goal of this study is to analyse whether Bitcoin behaves as a speculative asset or as a safe haven - as gold is often considered - it is interesting to evaluate the impact of EPU on the returns and volatility of Bitcoin and gold in the most extreme quantiles. Based on the definition of EPU, a more significant impact of EPU could be expected on the returns and volatility of Bitcoin and gold in its higher values when the feeling of investor insecurity is stronger. In addition, an advantage of quantile r egression with respect to simple linear regression with ordinary least squares is that quantile regression estimates are more robust with regard to extreme values in response measurements (Koenker, 2005).

Thus, the models of simple linear regression with ordinary least squares used to analyse the influence of EPU on the returns and volatility of Bitcoin and gold can be defined as:

$$
\begin{aligned}
& R_{i, t}=\alpha+\beta \mathrm{EPU}_{t}+\varepsilon_{t} \\
& V_{i, t}=\alpha+\beta \mathrm{EPU}_{t}+\varepsilon_{t}
\end{aligned}
$$

where $R_{i, t}$ and $R_{i, t}$ represent the returns and volatility of the asset $i$, respectively, on day $t, \alpha$ the constant of the model, $\mathrm{EPU}_{t}$ the EPU level on day $t, \beta$ the intensity of the influence of the fluctuations of $\mathrm{EPU}_{t}$ on $R_{i, t}$ and $V_{i, t}$, respectively, and $\varepsilon_{t}$ the error term.

To model the influence of EPU on the most extreme quantiles of the returns and volatility of Bitcoin and gold, the quantile regression models proposed can be defined as:

$$
\begin{aligned}
& R_{i, t}=\alpha_{\tau}+\beta_{\tau} \mathrm{EPU}_{t}+\varepsilon_{t, \tau} \\
& V_{i, t}=\alpha_{\tau}+\beta_{\tau} \mathrm{EPU}_{t}+\varepsilon_{t, \tau}
\end{aligned}
$$

being $\tau$ the quantile with a value between 0 and 1 . In the study, we focus on the most extreme quantiles, so $\tau$ will take the values of $0.01,0.05,0.1,0.25,0.75,0.9,0.95$ and 0.99 .

\begin{tabular}{|c|c|c|c|c|c|c|c|c|}
\hline & EPU & $R_{\text {Bit }}$ & $V_{1, \text { Bit }}$ & $V_{2, \text { Bit }}$ & $R_{\text {Gold }}$ & $V_{1, \text { Gold }}$ & $V_{2, \text { Gold }}$ & \\
\hline Mean & 108.530 & 0.0063 & 0.0714 & 0.8101 & 0.0001 & 0.0137 & 0.1572 & \\
\hline Median & 92.1700 & 0.0000 & 0.0426 & 0.4883 & 0.0007 & 0.0118 & 0.1350 & \\
\hline Minimum & 3.3200 & -0.5721 & 0.0000 & 0.0000 & -0.0954 & 0.0000 & 0.0000 & \\
\hline Maximum & 586.5500 & 3.3675 & 2.0000 & 12.625 & 0.0529 & 0.1127 & 1.2949 & Table I. \\
\hline Standard deviation & 65.0810 & 0.0919 & 0.1041 & 1.0917 & 0.0092 & 0.0084 & 0.0959 & Descriptive statistics of \\
\hline CV & 0.5997 & 14.7010 & 1.4591 & 1.3477 & 116.94 & 0.6103 & 0.6104 & the variables from the \\
\hline Asymmetry & 1.7127 & 16.9470 & 6.8572 & 4.4549 & -0.7605 & 2.8623 & 2.8652 & period 19 July $2010-11$ \\
\hline Kurtosis excess & 4.9469 & 579.6600 & 88.0270 & 29.173 & 9.8983 & 17.386 & 17.427 & April 2019 \\
\hline
\end{tabular}

\section{Results}

We studied the influence of EPU on the returns and volatility of Bitcoin and gold with linear regression with ordinary least squares and quantile regression.
Economic Policy Uncertainty and Bitcoin 
EJMBE 29,3

\section{4}

The simple linear regression model was used to analyse the influence of EPU on Bitcoin returns. (Table II) shows a positive but not significant $\beta$ coefficient. However, there is a positive and significant influence of EPU on gold returns. These results suggest that the uncertainty generated by governments and central banks has no explanatory power over Bitcoin returns. Based on this result, it could not be said that Bitcoin acts as a safe haven or hedge for the uncertainty surrounding the economic system. In turn, several studies have shown that EPU has a negative and significant impact on stock returns (Dzielinski, 2012; Antonakakis et al., 2013; Adjei and Adjei, 2017, amongst others). Consequently, the results do not support the assertion that Bitcoin plays the role of a simple speculative asset.

When studying the influence of EPU on Bitcoin and gold volatility using the volatility measure proposed by Chen and Zheng (2008) with simple linear regression (Table III), there is a positive and significant relationship between EPU and Bitcoin volatility, as well as between EPU and gold volatility with a significance level lower than 0.0001 .

Using Parkinson's (1980) volatility measure (Table IV), we observe that the relationship found with the measure of volatility of Chen and Zheng (2008) between EPU and Bitcoin and gold volatility is maintained with a significance level lower than 0.001 . Based on these results, it could be asserted that Bitcoin can take the role of a safe haven during times of uncertainty, as well as the role of a speculative asset, since investor insecurity - as described by EPU - has a positive impact on the movement of Bitcoin prices, behaviour that matches that of gold. With this result, following Fang et al. (2019), it could be said that Bitcoin behaves like a hedge or safe haven. Based on Eom et al. (2019), Bitcoin could also be considered as a speculative asset since it shows the typical characteristics of these assets: dependence on investor sentiment and high volatility.

However, since we are modelling the influence of a sentiment, as that generated by EPU on investors, it seems wise to take a closer look at the influence of EPU on the returns and volatility of Bitcoin and gold at its extreme levels (measured by its quantiles 0.01, 0.05, 0.1, $0.25,0.75,0.9,0.95$ and 0.9$)$. We do this by applying quantile regression.

Table $\mathrm{V}$ shows how the influence of EPU on Bitcoin and gold returns differs at lower and higher quantiles. At lower quantiles, it is found that EPU has a negative impact on Bitcoin returns, except at the 0.25 quantile, this impact being significant only at the 0.01 quantile. Regarding gold, it is found that EPU has a negative impact on gold returns at the 0.05 and 0.01 quantiles, but these impacts are not significant. However, at higher quantiles, the influence of EPU on Bitcoin returns turns out to be positive and significant in the 0.99 and 0.9 quantiles. Similarly, it is observed how EPU has a positive impact on gold returns in the quantiles $0.75,0.9,0.95$ and 0.99 , this impact being significant in the $0.75,0.9$ and 0.95 quantiles. The positive influence of EPU on Bitcoin returns found is in line with studies such as those by Bouri et al. (2017a), Selmi et al. (2018) and Demir et al. (2018). The fact that at the highest investor uncertainty levels (as expressed by EPU values) Bitcoin returns increase, conveys characteristics of a hedge or safe haven. Just like gold, Bitcoin shows an increase in its returns during more uncertain times, when a conventional speculative asset, such as stocks, would see its returns reduced.

Table II.

Estimates of the influence of EPU on Bitcoin and gold returns with the simple linear regression Model for the period 19 July 2010-11 April 2019

\begin{tabular}{lccccccccc}
\hline & \multicolumn{4}{c}{$R_{\text {Bit }}$} & \multicolumn{5}{c}{$R_{\text {Gold }}$} \\
Coefficients & Estimate & $\begin{array}{c}\text { Standard } \\
\text { error }\end{array}$ & $t$ value & $\operatorname{Pr}(>|t|)$ & Estimate & error & $t$ value & $\operatorname{Pr}(>|t|)$ \\
\hline (Intercept) & 0.00411 & 0.00317 & 1.2970 & 0.1946 & -0.00091 & 0.00037 & -2.458 & $0.0140^{* *}$ \\
EPU & 0.00002 & 0.00002 & 0.7901 & 0.4295 & 0.00001 & 0.00001 & 3.111 & $0.0019^{* * *}$
\end{tabular}

Note(s): $* * *, * *$ and $*$ indicate the significance at $1 \%, 5 \%$ and $10 \%$ levels, respectively 
Table III.

Estimates of the influence of EPU on

Bitcoin and gold volatility (Eqn 2) with the simple linear regression model for the period 19 July 2010-11 April 2019 


\section{EJMBE \\ 29,3}

Table IV.

Estimates of the influence of EPU on Bitcoin and gold volatility (Eqn 3) with the simple linear regression model for the period 19 July 2010-11 April 2019 


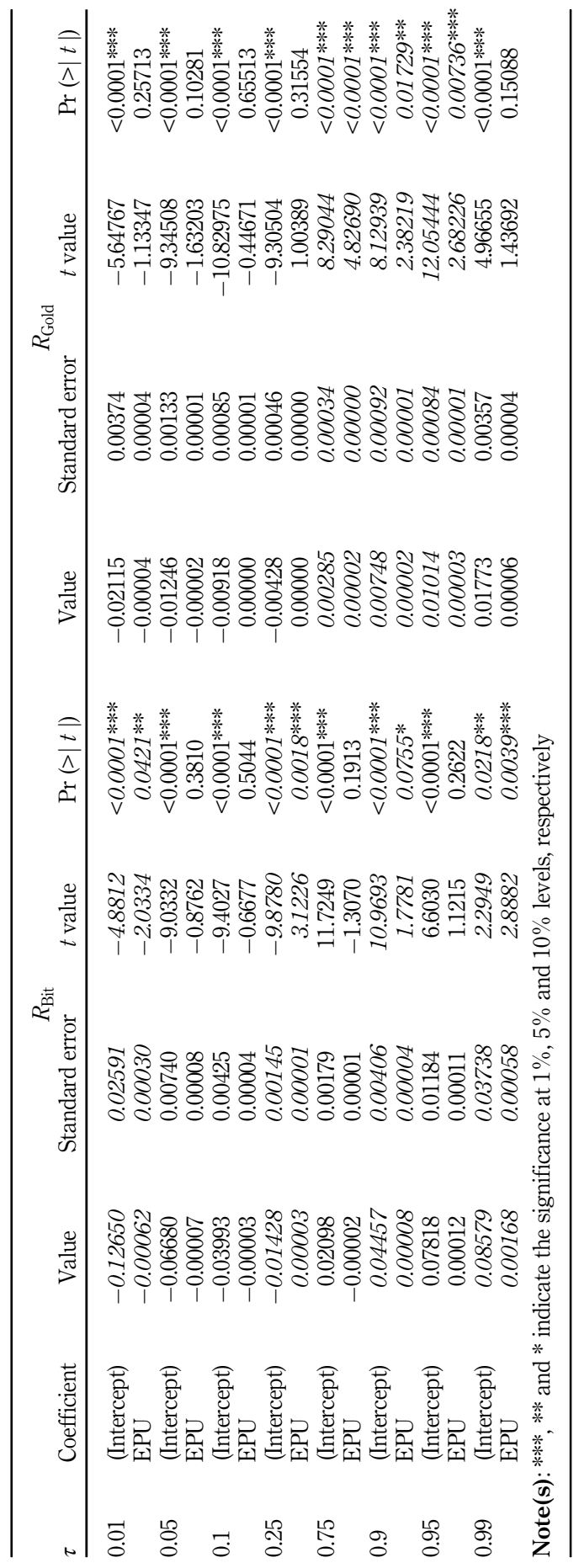

Table V. Estimates of the Influence of EPU on

Bitcoin and gold returns with the quantile regression model for the period 19 July 2010-11 
EJMBE 29,3
When analysing the influence of EPU on the volatility of Bitcoin in its extreme quantiles, taking the measure proposed by Chen and Zheng (2008) as a volatility estimator (Table VI), we can see how at lower quantiles (except 0.01), the influence of EPU on Bitcoin volatility is negative and significant. In contrast, EPU has a positive impact on gold volatility at lower quantiles (except 0.01), however, in no case is such impact significant. Focussing on higher quantiles, it is found that EPU is positively related to Bitcoin and gold volatility levels, being significant in the $0.75,0.9$ and 0.95 quantiles.

Taking Parkinson's volatility (1980) as a volatility estimator (Table VII), we observe that the influence of EPU on Bitcoin volatility is negative and significant in the lower quantiles, but positive and significant in the higher quantiles (except in the quantile 0.99 which is not significant). Similarly, using this volatility estimator, the influence of EPU on gold volatility is negative and significant in the lowest quantiles (except at the 0.25 quantile), but positive and significant at the highest quantiles.

These results show that the greater the uncertainty generated by governments and central banks regarding the economic policies they will carry out, the greater information asymmetry is (Akerlof, 1970) and, therefore, the greater the asymmetry in investors' individual expectations are. This result is in line with the findings of Eom et al. (2019) and Fang et al. (2019) and supports the literature that suggests that Bitcoin is not a simple means of exchange and store of value, but an investment asset, just like gold.

The findings regarding the influence of EPU on the volatility of Bitcoin allow us to affirm that Bitcoin is not only a means of exchange but that it also shows characteristics of an investment asset that reacts significantly to the uncertainty related to the economic system, just like gold. Regarding its consideration as a safe haven or a simple speculative value, the positive influence that EPU has on Bitcoin returns at higher quantiles, coincident with the behaviour of gold returns, allows us to defend that Bitcoin acts as a safe haven during more uncertain times.

\section{Conclusions}

The rapid growth of Bitcoin, its great capacity to recover during periods of turbulence and its high volatility, amongst other characteristics, has motivated a growing interest in the literature to understand the economic and financial determinants that could influence the price of Bitcoin. In this line, a debate has been generated regarding the role played by this cryptocurrency, is it a simple means of exchange and store of value, a speculative asset or a safe haven?

In this study, we aim to respond this question by studying the influence of EPU on Bitcoin returns and volatility. Our main assumption is that when investors feel insecure because of uncertainty regarding the fiscal, regulatory and monetary policies that may be implemented; hedges or safe havens should increase their returns and volatility, while the typical speculative assets should increase their volatility and reduce their returns. In order to obtain more robust results, we take gold as a reference safe haven and compare the behaviour of Bitcoin and gold against EPU.

The EPU measure of Baker et al. (2016) was used to analyse the influence of EPU on the returns and volatility of Bitcoin and gold for the period from 19 July 2010 to 11 April 2019. To thoroughly analyse this influence, two different methodologies were used: simple linear regression with ordinary least squares and quantile regression.

The results obtained when studying the influence of EPU on Bitcoin and gold returns by using simple linear regression with ordinary least squares have shown that EPU positively influences Bitcoin and gold returns for the whole sample. However, only the influence on gold returns is statistically significant. Analysing the influence of EPU on Bitcoin and gold volatility with two measures of volatility, shows that EPU positively and significantly 


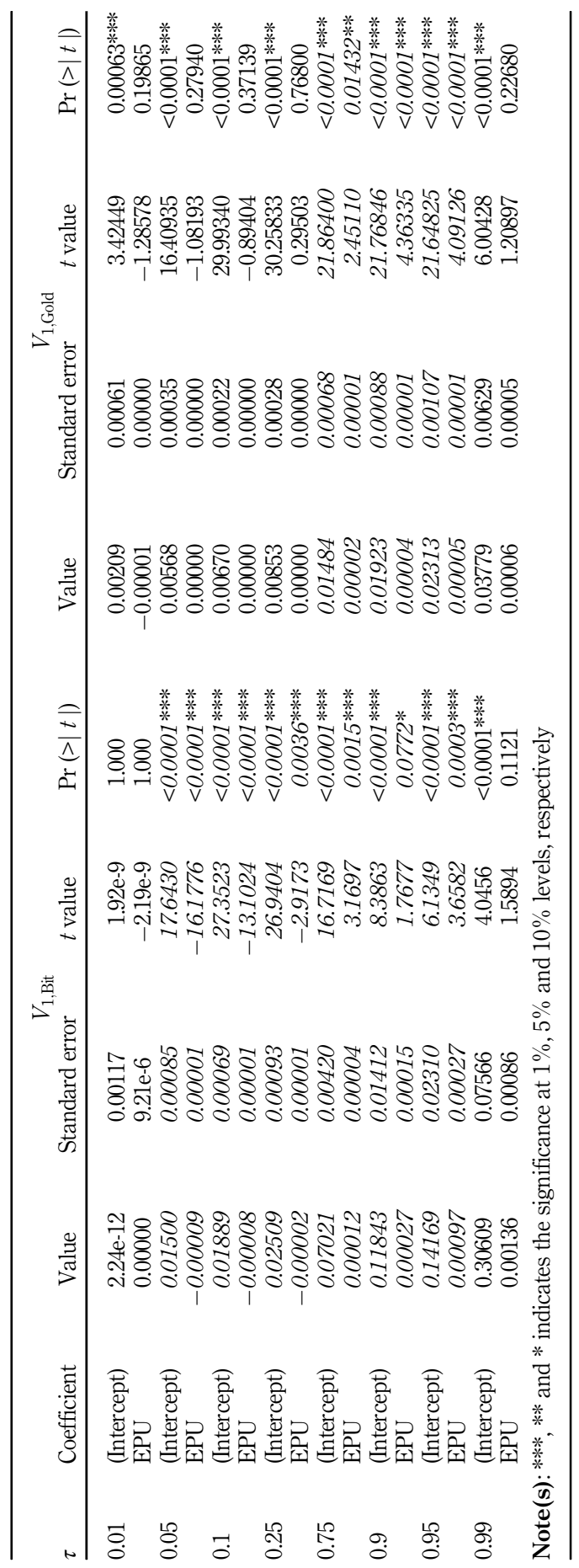

Table VI.

Estimates of the Influence of EPU on

Bitcoin and gold volatility (Eqn 2) with the quantile regression model for the period 19 July 2010-11 April 2019 


\section{EJMBE \\ 29,3}

360

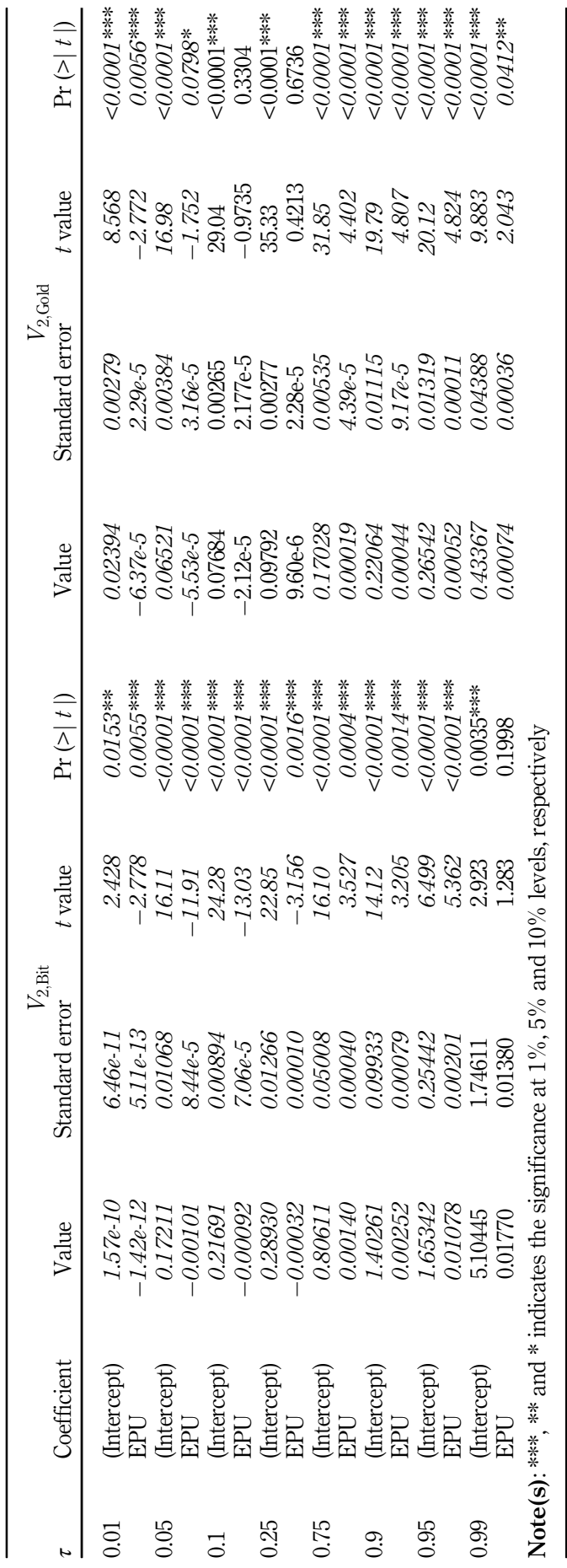

Table VII.

Estimates of the Influence of EPU on Bitcoin and gold volatility (Eqn 3) with the quantile regression model for the period 19 July 2010-11

April 2019 
influences the volatility of both Bitcoin and gold for the whole sample. Nevertheless, when analysing the influence of this uncertainty on extreme quantiles with quantile regression, it was found that EPU has a negative impact on Bitcoin returns in the lowest quantiles and a positive impact on these returns in the highest quantiles. The effect found of EPU on volatility shows that EPU increases Bitcoin and gold volatility at the highest quantiles, with no coincidence for the lowest quantiles.

These results suggest that Bitcoin does not only act as a means of exchange or store of value but it also has characteristics of investment assets, such as its dependence on investor sentiment and high volatility. In turn, the fact that Bitcoin returns increase in the highest quantiles, as gold does, supports the role of Bitcoin as a safe haven during more uncertain times and discards its role as a simple speculative asset, such as shares. Also, knowing that Bitcoin acts as a safe haven not only allows it to be considered as a tool to protect savings in times of economic uncertainty but also qualifies it as a relevant asset for constructing diversified portfolios.

These findings provide useful information to investors, both individuals and professionals, by demonstrating Bitcoin's behaviour in situations of uncertainty regarding economic policies. The fact that Bitcoin's returns and volatility are affected by EPU suggests that investors can use information on EPU to make better investment decisions about Bitcoin, allowing them to consider this cryptocurrency as another investment instrument, and not as a means of exchange, which was the main purpose for which it was created. Based on this, investors can benefit from this information in three ways. First, by demonstrating the influence of EPU on Bitcoin's returns and volatility, investors can use information on EPU to make better investment decisions about Bitcoin. Second, the finding that Bitcoin can be a safe haven, like gold, allows investors to consider this cryptocurrency as a tool to protect their savings in times of economic uncertainty. Finally, the role played by Bitcoin found, in turn, may be relevant in the formation of investment portfolios, because this cryptocurrency can contribute to the construction of better diversified portfolios. Our findings are also relevant for economic policy makers, demonstrating how the uncertainty surrounding their policy development and implementation has a manifest impact on investment assets.

Although the results obtained in this study are relevant for the literature on the role played by Bitcoin in the face of uncertainty, this study is not without limitations. In this study, we take as a measure of economic policy uncertainty the daily USEPU index, as well as the prices of Bitcoin in US\$. Future research could analyse whether our results are sensitive to the use of other uncertainty measures and other Bitcoin data denominated in a currency other than US\$. Likewise, in this work the effect of EPU on other cryptocurrencies has not been considered. The study of more cryptocurrencies could help understand the potential determinants of the behaviour of these cryptocurrencies in the face of EPU. Finally, this work has not been raised to obtain efficient portfolios including Bitcoin, being interesting to advance in the study of the construction of efficient portfolios incorporating these cryptocurrencies. Despite the fact that there are already incipient studies in this line, there is still much to be done.

\section{References}

Aalborg, H.A., Molnár, P. and de Vries, J.E. (2019), "What can explain the price, volatility and trading volume of Bitcoin?”, Finance Research Letters, Vol. 29, pp. 255-265.

Adjei, F.A. and Adjei, M. (2017), "Economic policy uncertainty, market returns and expected return predictability", Journal of Financial Economic Policy, Vol. 9 No. 3, pp. 242-259.

Akerlof, G. (1970), "The market for 'lemons': quality uncertainty and the market mechanism”, The Quarterly Journal of Economics, Vol. 84 No. 3, pp. 488-500.

Al-Khazali, O., Elie, B. and Roubaud, D. (2018), "The impact of positive and negative macroeconomic news surprises: gold versus Bitcoin”, Economics Bulletin, Vol. 38 No. 1, pp. 373-382.

\section{Economic Policy \\ Uncertainty and Bitcoin}


EJMBE 29,3
Antonakakis, N., Chatziantoniou, I. and Filis, G. (2013), "Dynamic co-movements of stock market returns, implied volatility and policy uncertainty", Economics Letters, Vol. 120 No. 1, pp. 87-92.

Baker, S.R., Bloom, N. and Davis, S.J. (2016), "Measuring economic policy uncertainty", The Quarterly Journal of Economics, Vol. 131 No. 4, pp. 1593-1636.

Baur, D.G., Hong, K. and Lee, A.D. (2018), "Bitcoin: medium of exchange or speculative assets?", Journal of International Financial Markets, Institutions and Money, Vol. 54, pp. 177-189.

Bouri, E., Gupta, R., Tiwari, A.K. and Roubaud, D. (2017a), "Does Bitcoin hedge global uncertainty? Evidence from wavelet-based quantile-in-quantile regressions", Finance Research Letters, Vol. 23, pp. 87-95.

Bouri, E., Molnár, P., Azzi, G., Roubaud, D. and Hagfors, L.I. (2017b), "On the hedge and safe haven properties of Bitcoin: is it really more than a diversifier?", Finance Research Letters, Vol. 20, pp. 192-198.

Bouri, E., Gupta, R., Lahiani, A. and Shahbaz, M. (2018a), “Testing for asymmetric nonlinear short-and long-run relationships between Bitcoin, aggregate commodity and gold prices", Resources Policy, Vol. 57, pp. 224-235.

Bouri, E., Gupta, R., Lau, C.K.M., Roubaud, D. and Wang, S. (2018b), "Bitcoin and global financial stress: a copula-based approach to dependence and causality in the quantiles", The Quarterly Review of Economics and Finance, Vol. 69, pp. 297-307.

Bouri, E., Shahzad, S.J.H. and Roubaud, D. (2019), “Co-explosivity in the cryptocurrency market", Finance Research Letters, Vol. 29, pp. 178-183.

Brandvold, M., Molnár, P., Vagstad, K. and Valstad, O.C.A. (2015), "Price discovery on Bitcoin exchanges", Journal of International Financial Markets, Institutions and Money, Vol. 36, pp. 18-35.

Cheah, E.T. and Fry, J. (2015), "Speculative bubbles in Bitcoin markets? An empirical investigation into the fundamental value of Bitcoin", Economics Letters, Vol. 130, pp. 32-36.

Chen, M. and Zheng, Z. (2008), "The impact of short selling on the volatility and market liquidity of stock markets: evidence from Hong Kong market”, in Wen, F.H. and Yu, L. (Eds), Advances in Business Intelligence and Financial Engineering, Atlantis Press, Paris.

Ciaian, P., Rajcaniova, M. and Kancs, D.A. (2016), “The economics of BitCoin price formation”, Applied Economics, Vol. 48 No. 19, pp. 1799-1815.

Corbet, S., Lucey, B. and Yarovaya, L. (2018), "Datestamping the Bitcoin and ethereum bubbles", Finance Research Letters, Vol. 26, pp. 81-88.

Demir, E., Gozgor, G., Lau, C.K.M. and Vigne, S.A. (2018), "Does economic policy uncertainty predict the Bitcoin returns? An empirical investigation", Finance Research Letters, Vol. 26, pp. 145-149.

Dowd, K. (2014), New Private Monies: A Bit-Part Player?, Institute of Economic Affairs Monographs, Hobart Paper, 174, London.

Dyhrberg, A.H. (2016), "Hedging capabilities of bitcoin. Is it the virtual gold?", Finance Research Letters, Vol. 16, pp. 139-144.

Dzielinski, M. (2012), "Measuring economic uncertainty and its impact on the stock market", Finance Research Letters, Vol. 9 No. 3, pp. 167-175.

Eom, C., Kaizoji, T., Kang, S.H. and Pichl, L. (2019), "Bitcoin and investor sentiment: statistical characteristics and predictability", Physica A: Statistical Mechanics and its Applications, Vol. 514, pp. 511-521.

Fang, L., Bouri, E., Gupta, R. and Roubaud, D. (2019), "Does global economic uncertainty matter for the volatility and hedging effectiveness of Bitcoin?", International Review of Financial Analysis, Vol. 61, pp. 29-36.

Guesmi, K., Saadi, S., Abid, I. and Ftiti, Z. (2019), "Portfolio diversification with virtual currency: evidence from Bitcoin”, International Review of Financial Analysis, Vol. 63, pp. 431-437. 
Huisman, R., van der Sar, N.L. and Zwinkels, R.C. (2012), "A new measurement method of investor overconfidence”, Economics Letters, Vol. 114 No. 3, pp. 69-71.

Koenker, R. (2005), Quantile Regression, Econometric Society Monograph Series 38, Cambridge University Press, Cambridge.

Kristoufek, L. (2013), "BitCoin meets google trends and wikipedia: quantifying the relationship between phenomena of the internet era", Scientific Reports, Vol. 3 No. 3415, doi: 10.1038/ srep03415.

Kristoufek, L. (2015), "What are the main drivers of the Bitcoin price? Evidence from wavelet coherence analysis", PloS One, Vol. 10 No. 4, e0123923.

Luther, W.J. and Salter, A.W. (2017), "Bitcoin and the bailout", The Quarterly Review of Economics and Finance, Vol. 66, pp. 50-56.

Molnár, P. (2012), "Properties of range-based volatility estimators", International Review of Financial Analysis, Vol. 23, pp. 20-29.

Nakamoto, S. (2008), "Bitcoin: a peer-to-peer electronic cash system", available at: https://bitcoin.org/ bitcoin.pdf.

Parkinson, M. (1980), "The extreme value method for estimating the variance of the rate of return", Journal of Business, Vol. 53, pp. 61-65.

Polasik, M., Piotrowska, A.I., Wisniewski, T.P., Kotkowski, R. and Lightfoot, G. (2015), "Price fluctuations and the use of Bitcoin: an empirical inquiry", International Journal of Electronic Commerce, Vol. 20 No. 1, pp. 9-49.

Selmi, R., Mensi, W., Hammoudeh, S. and Bouoiyour, J. (2018), "Is Bitcoin a hedge, a safe haven or a diversifier for oil price movements? A comparison with gold”, Energy Economics, Vol. 74, pp. 787-801.

Shahzad, S.J.H., Bouri, E., Roubaud, D., Kristoufek, L. and Lucey, B. (2019), "Is Bitcoin a better safehaven investment than gold and commodities?", International Review of Financial Analysis, Vol. 63, pp. 322-330.

Wang, G.J., Xie, C., Wen, D. and Zhao, L. (2018), "When Bitcoin meets economic policy uncertainty (EPU): measuring risk spillover effect from EPU to Bitcoin”, Finance Research Letters, doi: 10. 1016/j.frl.2018.12.028.

Weber, B. (2014), "Bitcoin and the legitimacy crisis of money", Cambridge Journal of Economics, Vol. 40 No. 1, pp. 17-41.

\section{Corresponding author}

Jessica Paule-Vianez can be contacted at: jessica.paule@urjc.es
Economic Policy

Uncertainty and Bitcoin 